\title{
Anti-tumor necrosis factor treatment in ankylosing spondylitis may not relate to poor prognosis in COVID-19
}

\author{
Nesrin Şen (1), Mehmet Engin Tezcan (D) \\ Department of Rheumatology, University of Health Sciences, \\ Kartal Dr. Lütfi Kırdar Training and Research Hospital, Istanbul, Turkey
}

Severe acute respiratory syndrome coronavirus 2 (SARS-CoV-2), the novel coronovirus form, has emerged as a health problem since it was first identified in December 2019. The virus is responsible for coronavirus disease 2019 (COVID-19). COVID-19 is a multisystemic disease that mainly leads to viral pneumonia and acute respiratory distress syndrome. ${ }^{1}$ Older adults, people who have severe underlying medical conditions and patients on immunosuppressive drugs for rheumatologic diseases seem to be at higher risk for developing more severe complications from COVID-19.1,2 Therefore, it would be speculated that anti-tumor necrosis factor (anti-TNF) drugs may exert a negative influence on COVID-19. However, some promising data showed that antiTNF drugs may be a treatment option during the severe forms of the disease such as macrophage activation syndrome (MAS). ${ }^{3}$ In this article, we presented two ankylosing spondylitis patients who contracted COVID-19 disease while on anti-TNF therapy.

Case 1- A 47-year-old male patient with AS applied to the emergency service with the symptoms of fever, shortness of breath and non-productive cough. He had been on etanercept treatment for three years. He had no other known comorbidities. Even though the polymerase chain reaction (PCR) test for SARS-CoV-2 was found negative, he was diagnosed as COVID-19 due to thorax computed tomography $(\mathrm{CT})$ signs relevant to viral pneumonia (Figure 1a). Hydroxychloroquine and azithromycin were started. Patient's baseline high C-reactive protein $(65.5 \mathrm{mg} / \mathrm{L})$ was the only laboratory test related with poor prognosis. Thereafter, he was discharged with full recovery at the fifth day of hospitalization.

Case 2- A 44-year-old male patient with AS applied to emergency service with symptoms of fever and shortness of breath while on adalimumab treatment. Furthermore, he also suffered from bronchial asthma. His PCR test for SARSCoV-2 was found positive and thorax CT was relevant to viral pneumonia (Figure 1b). Moreover, low lymphocyte level $(500 \mu / \mathrm{L})$ was the main laboratory value associated with worse outcome. Afterwards, he received hydroxychloroquine and azithromycin concomitant with oxygen support through nasal cannula. On the third day of treatment, he was discharged without need for oxygen support.

Received: May 26, 2020 Accepted: June 05, 2020 Published online: June 25, 2020

Correspondence: Nesrin Şen, MD. SBÜ Dr. Lütfi Kırdar Eğitim ve Araştırma Hastanesi Romatoloji Bölümü, 34890 Kartal, İstanbul, Türkiye. Tel: +90216 - 4583000 e-mail: sennes77@yahoo.com Arch Rheumatol 2021;36(1):142-143. 

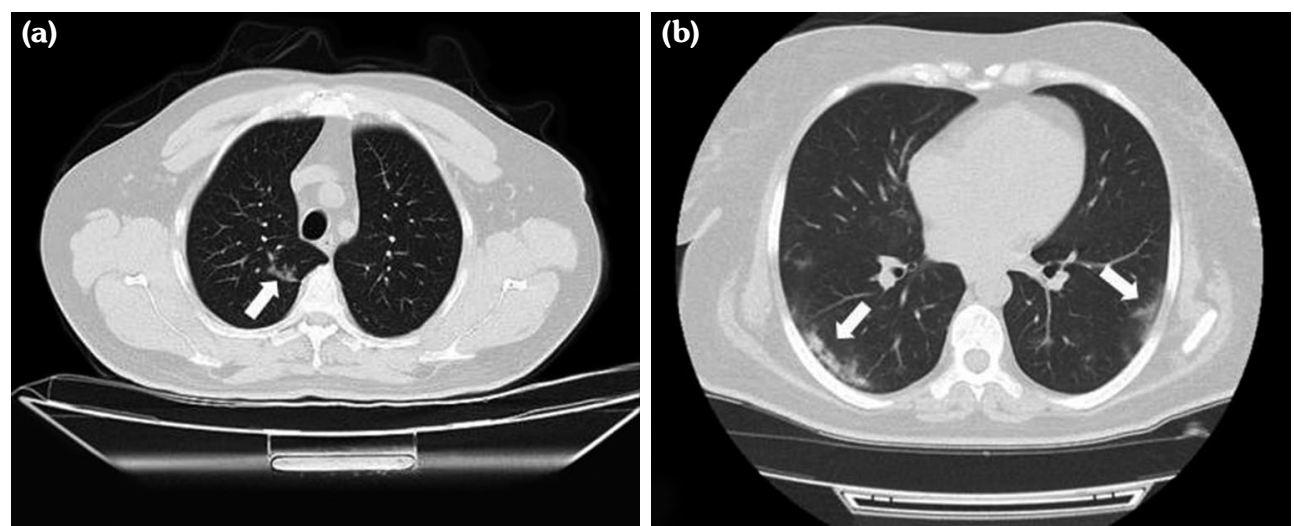

Figure 1. (a) Thorax computed tomography of Case 1, white arrow indicating ground glass opacity relevant to viral pneumonia. (b) Thorax computed tomography of Case 2, white arrows indicating bilateral and multiple ground glass opacities relevant to viral pneumonia.

Immunosuppressive drugs including antiTNFs enhanced the infection risk. Herein, respiratory tract infections are the oftenest. However, anti-TNFs may have anti-viral activity for serious respiratory syncytial virus and influenza infections. Here, anti-TNFs may lower the risk of lower lung injury. Also, increased levels of TNF-alpha were reported along with several inflammatory cytokines in COVID-19. ${ }^{3}$ Furthermore, viral entry of the SARS-Cov-2 via angiotensin converting enzyme-2 receptor was coupled with TNF-alpha production. Therefore, anti-TNFs may block the viral entry. ${ }^{4}$ Although both patients with AS were on anti-TNFs while contracting the disease, they were discharged after treatment without need for further support. Herein, although, the upper-mentioned recent findings and hypothesis about TNF-alpha's role in the pathogenesis of COVID-19 and our patient's favorable outcome for COVID-19, it would not be possible to accept anti-TNF drugs as a treatment choice for COVID-19. However, we thought that anti-TNFs may not pose a risk for serious COVID-19 as predicted before. Also, clinical trials should be conducted for evaluating the anti-TNFs' effect on COVID-19 even during the viral spreading phase and before/during the disease coupled with MAS. ${ }^{5}$

\section{Declaration of conflicting interests}

The authors declared no conflicts of interest with respect to the authorship and/or publication of this article.

\section{Funding}

The authors received no financial support for the research and/or authorship of this article.

\section{REFERENCES}

1. Rothan HA, Byrareddy SN. The epidemiology and pathogenesis of coronavirus disease (COVID-19) outbreak. J Autoimmun 2020;109:102433.

2. Onder G, Rezza G, Brusaferro S. Case-Fatality Rate and Characteristics of Patients Dying in Relation to COVID-19 in Italy. JAMA 2020. [Online ahead of print]

3. Favalli EG, Ingegnoli F, De Lucia O, Cincinelli G, Cimaz R, Caporali R. COVID-19 infection and rheumatoid arthritis: Faraway, so close! Autoimmun Rev 2020;19:102523.

4. Haga S, Yamamoto N, Nakai-Murakami C, Osawa Y, Tokunaga K, Sata T, et al. Modulation of TNFalpha-converting enzyme by the spike protein of SARS-CoV and ACE2 induces TNF-alpha production and facilitates viral entry. Proc Natl Acad Sci U S A 2008;105:7809-14.

5. Feldmann M, Maini RN, Woody JN, Holgate ST, Winter G, Rowland M, et al. Trials of anti-tumour necrosis factor therapy for COVID-19 are urgently needed. Lancet 2020;395:1407-9. 